\title{
Erratum to: Synthesis of Cholesterol-Conjugated Magnetic Nanoparticles for Purification of Human Paraoxonase 1
}

\author{
Zahoor Qadir Samra ${ }^{1} \cdot$ Sadaf Shabir $^{1}$. \\ Zainab Rahmat ${ }^{1}$ - Mariam Zaman ${ }^{1}$. Aqsa Nazir ${ }^{1}$. \\ Nadia Dar ${ }^{2} \cdot$ Muhammad Amin Athar ${ }^{1}$
}

Published online: 18 October 2016

(C) Springer Science+Business Media New York 2016

\section{Erratum to: Appl Biochem Biotechnol (2010) 162:671-686 \\ DOI 10.1007/s12010-009-8840-4}

The original version of this article unfortunately contained a mistake. One of the authors name was misspelled where Zainab Rehmat should have been Zainab Rahmat. The authors hereby publish the correct name stated above.

The online version of the original article can be found at http://dx.doi.org/10.1007/s12010-009-8840-4.

Zahoor Qadir Samra

samra201@yahoo.com

1 Institute of Biochemistry and Biotechnology, Quaid-i-Azam Campus, University of the Punjab, Lahore 54590, Pakistan

2 Jinnah Degree College for Women, Mozang Road, Lahore 54590, Pakistan 